\title{
Thin Molecular Films of Supramolecular Porphyrins
}

\author{
KOITI ARAKI, SIMONE DE SOUZA LIMA and HERBERT WINNISCHOFER \\ Instituto de Química - USP, Cx. Postal 26.077 - 05599-970 - São Paulo, SP, Brazil \\ Manuscript received on September 8, 1999; accepted for publication on September 15, 1999; \\ presented by José M. RIVERos
}

\begin{abstract}
A relevant series of symmetric supramolecular porphyrins has been obtained by attaching four [ $\left.\mathrm{Ru}{ }^{\mathrm{II}}(\mathrm{bipy})_{2} \mathrm{Cl}\right]$ groups to the pyridyl substituents of meso-tetra(4-pyridyl)porphyrin and its metallated derivatives. These compounds display a rich electrochemistry and versatile catalytic, electrocatalytic and photochemical properties, associated with the ruthenium-bipyridine and the porphyrin complexes. These properties can be transferred to the electrodes by attaching thin molecular films of the compounds, by dip-coating, electrostatic assembly or electropolymerization. In this way, the interesting properties of those supermolecules and supramolecular assemblies can be used to prepare molecular devices and sensors.
\end{abstract}

Key words: Polynuclear porphyrins, thin molecular films, chemical sensors.

\section{INTRODUCTION}

Supramolecular chemistry (Lehn 1988) involves the formation of spatially organized assemblies of two or more molecular entities through covalent bonds, electrostatic forces or weak van der Waals interactions. There is a huge amount of known and newly prepared chemicals that can be combined generating an infinite number of supramolecular assemblies and materials, exhibiting interesting catalytic, electrocatalytic, photoelectrochemical and molecular recognition properties.

The porphyrins and ruthenium polypyridines (Kalyanasundaram 1992; Bedioui et al. 1996) are two classes of compounds exhibiting most of the above mentioned molecular properties. Consequently, the build-up of polymetallic supermolecules based on porphyrins and ruthenium bipyridine complexes has been pursued with great interest. A relevant series of symmetric polynuclear species has

Correspondence to:

Koiti Araki, koiaraki@iq.usp.br been obtained by attaching four $\left[\mathrm{Ru}^{\mathrm{II}}(\text { bipy })_{2} \mathrm{Cl}\right]$ groups to the pyridyl substituents of meso-tetra(4pyridyl)porphyrin and its metallated derivatives (Toma \& Araki 2000). These compounds display a rich electrochemistry and versatile catalytic and photochemical properties, associated with the ruthenium-bipyridine complexes and the porphyrin ring. Another interesting property is their ability to form homogeneous and adherent films, which make possible the transfer of the properties of the supramolecular porphyrins to an electrode surface. This is of paramount importance for the generation of new devices, sensors and interfaces. In this short review we report our studies on thin molecular films of supramolecular porphyrins and give a preview of the advances with a couple of new electropolymerizable porphyrin series.

\section{THIN MOLECULAR FILMS}

Thin molecular films can be defined as those formed by less than a hundred of monolayers and whose 
properties are defined mainly by the molecular and supramolecular properties of their components. So, it is possible to devise new materials and transfer their chemical, photochemical and photophysical properties to solid substrates.

There are many methods to obtain thin molecular films. Two well established ones are the molecular beam epitaxy and thermoevaporation methods. However, these are vacuum techniques generally limited to volatile and thermally stable compounds. Milder methods can be used to obtain thin films with a high degree of molecular organization, for example by self-assembly of thiols on gold surfaces, by Langmuir/Blodget (LB) method and electrostatic assembly. The last two methods can be used to obtained multilayer molecular films with variable composition, in contrast with the first one that almost exclusively generates monolayers or submonolayers.

The electrostatic assembly method was restricted to materials in which at least one of the species was a macromolecular poly-ion (Cooper et al. 1995). However, the electrostatic interaction between two oppositely charged species can generate very insoluble materials. So, by using an "in-situ" ion-exchange method involving tetraruthenated porphyrins (TRP) and tetra-(4-sulphonatephenyl)porphyrins (TPPS) we were able to obtain homogeneous bilayered porphyrin films (Araki et al. 1996). This is a method that has a close resemblance with the LB method, because the resulting materials are layered and it is possible to combine many different molecular species at will. Furthermore, the thickness can be controlled at molecular level, as can be inferred by the linear increase of the absorbance (Fig. 1) and thickness as a function of the number of bilayers.

\section{FILM PROPERTIES}

The supramolecular porphyrin films have electrochemical, electrocatalytic, photoelectrochemical and also semiconducting properties. However, the dip-coated materials were relatively soluble in aqueous solution, even in the presence of an excess of lithium trifluoromethanesulfonate (counter-anion), used as electrolyte. To address this problem we devised a method for electrostatic assembling cationic and anionic porphyrins to obtain bilayered materials, exhibiting good stability and low solubility in aqueous solution. The properties of both types of films will be presented in the following paragraphs.

The electrochemistry of M-TRP films is defined by the properties of the peripheral ruthenium complexes and the porphyrin ring. In aqueous solution, the potential is limited to about -1.0 to $+1.0 \mathrm{~V}$ range, such that only the $\mathrm{Ru}^{3+/ 2+}$ and the $\mathrm{M}^{3+/ 2+}$ redox reactions of the metal ion (Fe, Co and $\mathrm{Mn}$ ) coordinated to the porphyrin ring can be accessed. For example, dip-coated NiTRP films (Araki et al. 1995) exhibit only the reversible pair of waves corresponding to $\mathrm{Ru}^{3+/ 2+}$ couple, at $0.92 \mathrm{~V}$. When this modified electrode is used, the typical reversible response of a $\left[\mathrm{Fe}(\mathrm{CN})_{6}\right]^{4-}$ sample solution is not observed at $0.41 \mathrm{~V}$. Instead, only a sharp and intense oxidation peak is found at the beginning of the $\mathrm{Ru}(\mathrm{II} / \mathrm{III})$ wave. This is an evidence that the film is acting as an insulating barrier, except at potentials in which some $\mathrm{Ru}(\mathrm{III})$ complexes are formed. This is evidence that the mechanism of conduction is by electron-hopping and the film is homogeneous enough to completely avoid the ferrocyanide ion to reach the electrode surface. In fact, the system NiTRP film/ferrocyanide has a diode-like behavior, allowing the transport of electrons from the solution to the electrode, but not in the opposite direction.

The TRP modified glassy carbon electrodes are photoelectrochemically active. For example, an electrode dip-coated with ZnTRP generates a photocurrent (Araki \& Toma 1994) when irradiated with visible light in an electrochemical cell, in the presence of dissolved molecular oxygen. Electrodes modified with electrostatically assembled ZnTRP/TPPS films exhibit the same behavior and the photoaction spectrum is similar to the spectrum of the film (Araki et al. 1996), confirming its photoelectrochemical activity.

Furthermore, the TRP modified electrodes have electrocatalytic properties, useful for the preparation 

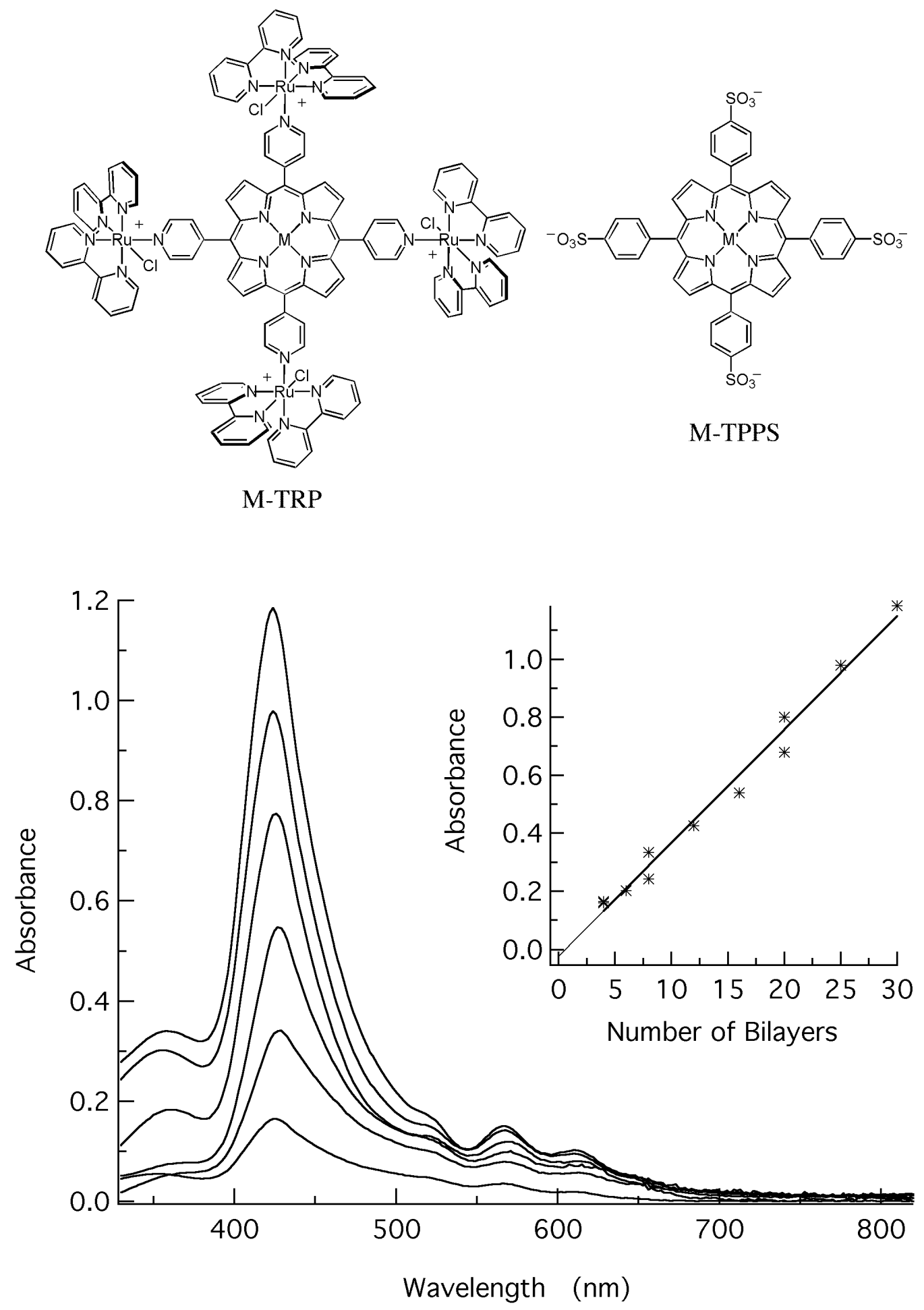

Fig. 1 - Top: Structures of M-TRP and M'-TPPS. Bottom: Electronic spectra of 4, 8, 16, 20, 25 and 30 bilayer films of ZnTRP/TPPS on ITO. Inset: linear growth of the absorbance as a function of the number of bilayers. 
of chemical sensors and devices. On the other hand, there is an increasing pressure to have more sensitive and specific sensors to identify and quantify a myriad of substrates; especially those involved in key biological functions and of environmental interest. M-TRP modified electrodes were shown to be useful in the detection of nitrite, sulfite, ascorbic acid, dopamine and NADH, by flow injection analysis (Toma \& Araki 2000). For all those substrates a sensibility in the $\mu \mathrm{M}$ level or less was reached. In fact, the electrocatalytic activity of the CoTRP/ZnTPPS sensor was used to perform the analysis of sulfite content in wines (Azevedo et al. 1999). The results were very similar to those obtained by using standard methods, but the FIA method has the advantage of being faster, easier to use and more reproducible.

\section{NEW SYSTEMS}

The methods of dip-coating and electrostatic assembly are very convenient, but it is not possible to deposit the porphyrin films on a restricted area on the substrate surface. This is a very important feature for the design and preparation of a multisensor device in which each microelectrode of an array is covered with a thin film of a specific material. In this case, even the Langmuir-Blodget and thermoevaporation methods are not suitable, being preferable to use the electropolymerization technique. This is a general and convenient method for the deposition of stable and insoluble films only on the polarized electrode surfaces.

So, two new supramolecular porphyrin series are being studied and the preliminary results are shown below. The first one is based on the electropolymerization properties of 5-chloro-1,10phenanthroline, 5ClPhen, ligand (Fussa-Rydel et al. 1989). The corresponding supramolecular porphyrin species, ETRP, was obtained by substituting the $\left[\mathrm{Ru} \text { (bipy) }{ }_{2} \mathrm{Cl}\right]^{+}$complexes of TRP by $\left[\mathrm{Ru}(5 \mathrm{ClPhen})_{2} \mathrm{Cl}\right]^{+}$groups. Consequently, the ETRP molecule has eight carbon atoms able to form C-C bonds per porphyrin supermolecule, enabling the formation of a polymeric network. Quite homo- geneous and electrochemically active films were obtained as can be seen in Figure 2, where the structure and the cyclic voltammogram of the free-base prototype is shown. The waves at $1.04 ;-0.64 ;-0.98$ and $-1.13 \mathrm{~V}$ can be ascribed to the $\mathrm{Ru}^{3+} / \mathrm{Ru}^{2+}, \mathrm{P}^{0} / \mathrm{P}^{-}$, $\mathrm{P}^{-} / \mathrm{P}^{2-}$ and

\section{$\left[\mathrm{Ru}(5 \mathrm{ClPhen})_{2} \mathrm{Cl}\right] /\left[\mathrm{Ru}(5 \mathrm{ClPhen})(5 \mathrm{ClPhen})^{-} \mathrm{Cl}\right]$}

redox processes.

By coordinating $\left[\mathrm{Fe}(\mathrm{CN})_{5}\right]^{3-}$ groups to meso3-pyridylporphyrin, it was obtained the prototype species of the second series of electropolymerizable supermolecule, TPCFP. In this case, it is possible to generate quite insoluble Prussian blue like materials (Toma et al. 1993) simply by adding transition metal ions to its aqueous solution. These are amorphous solids, but the films obtained by controlled deposition probably have a high degree of molecular organization. The films prepared by electrochemical deposition on nickel electrodes are very homogeneous and probably contain channels sided by porphyrin rings and Prussian blue like structures. This kind of structure is adequate for the occurrence of molecular recognition and electrocatalysis, and consequently for the preparation of chemical microsensors. In Figure 3 are shown the electronic spectrum and the cyclic voltammogram of a TPCFP film obtained on nickel electrode, confirming its electrochemical activity. The Soret and Q bands were found at 417, 526, 562, 599 and $655 \mathrm{~nm}$, confirming the presence of porphyrin in the material. Furthermore, the spectrum of the TPCFP in aqueous solution presents a shoulder at $435 \mathrm{~nm}$, assigned to the $\mathrm{Fe}^{\mathrm{II}}(\mathrm{d} \pi) \rightarrow$ $\mathrm{py}\left(\mathrm{p} \pi^{*}\right)$ charge transfer transition, which confirms the coordination of the pentacyanoferrate groups to the pyridine moieties of the porphyrin.

\section{FINAL REMARKS}

Many interesting supramolecular porphyrin systems can be devised in order to prepare thin molecular films by different methods. In this way, their molecular and supramolecular properties can be transferred to electrode surfaces and used in molecular devices. The new electropolymerizable 


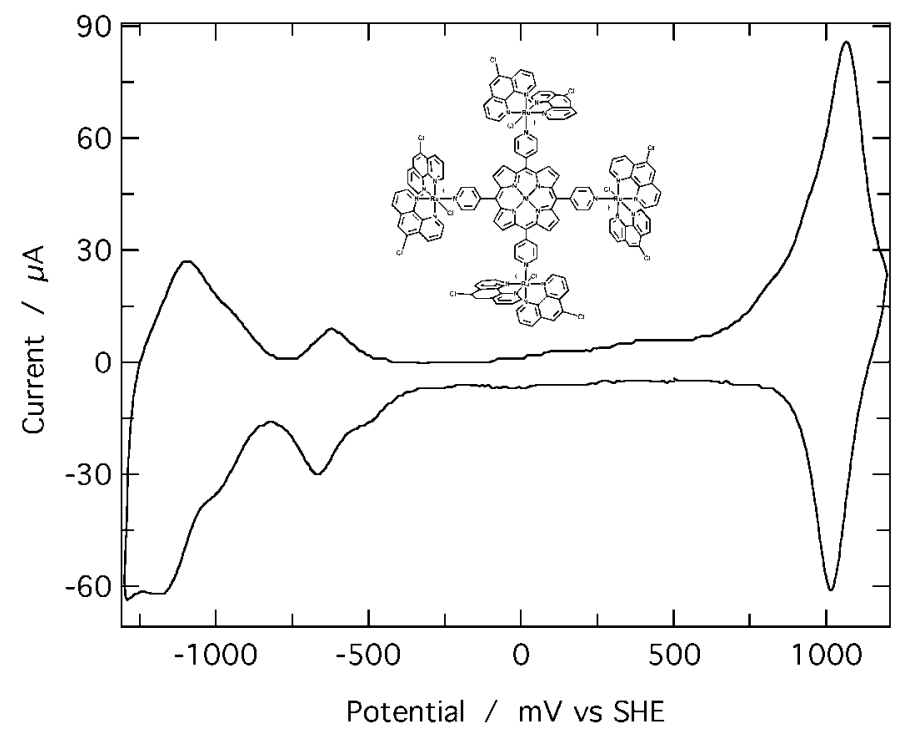

Fig. 2 - Cyclic voltammogram of a polymeric film of ETRP obtained by reductive electropolymerization of a dip-coated film of the monomer on a platinum electrode, in acetonitrile, $\mathrm{TEAClO}_{4} 0.1 \mathrm{M}$. Inset: Structure of ETRP Molecule.

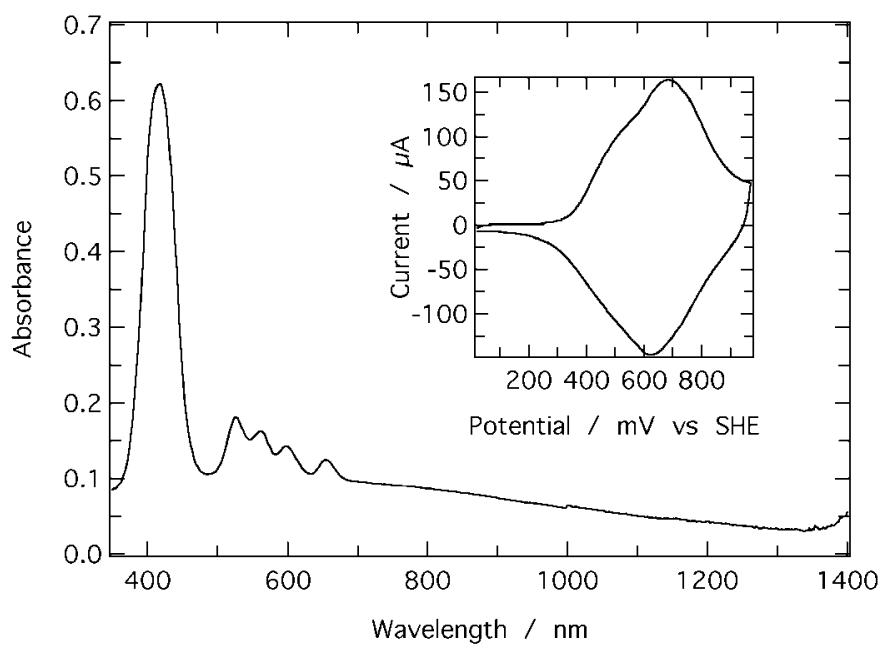

Fig. 3 - Electronic spectrum of a Prussian blue like film of TPCFP/ $/ \mathrm{Ni}^{2+}$ grown on polished nickel electrode by cronopotentiometry, $i=100 \mu \mathrm{A}, \mathrm{t}$ $=20 \mathrm{~s}, \mathrm{KCl} 0.20 \mathrm{M}$. Inset: cyclic voltammogram of the modified electrode in $\mathrm{KCl} 0.20 \mathrm{M}$. 
porphyrins are adequate to prepare molecular films on specific electrodes in an individually addressable electrode array, making possible the preparation of sensors that may respond simultaneously to multiple substrates.

\section{ACKNOWLEDGEMENTS}

We gratefully acknowledge the Brazilian agencies FAPESP and CNPq for the financial support.

\section{REFERENCES}

Araki K \& Toma \& HE 1994. Luminescence, Spectroelectrochemistry and Photoelectrochemical Properties of a Tetraruthenated Zinc Porphyrin. J Photochem Photobiol A- Chem 83: 245-250.

Araki K, Angnes L \& Toma HE 1995. Rectifying Properties and Photoconductivity of Tetraruthenated Nickel Porphyrin Films. Adv Materials 7: 554-559.

Araki K, Wagner MJ \& Wrighton MS 1996. Layerby-layer growth of electrostatically assembled multilayer porphyrin films. Langmuir 12: 5393-5398.

Azevedo CMN, Araki K, Toma HE \& Angnes L 1999. Determination of sulfur dioxide in wines by gasdiffusion flow injection analysis utilizing modified electrodes with electrostatically assembled films of tetraruthenated porphyrin. Anal Chim Acta 387: 175-180.
Bedioui F, Devynck J \& BiedCharreton C 1996. Electropolymerized manganese porphyrin films as catalytic electrode materials for biomimetic oxidations with molecular oxygen. $\mathrm{J} \mathrm{Mol} \mathrm{Cat} \mathrm{A-Chemical}$ 113: $3-11$.

Cooper TM, Campbell AL \& Crane RL 1995. Formation of Polypeptide-Dye Multilayers By an Electrostatic Self-Assembly Technique. Langmuir 11: 2713-2718.

Fussa-Rydel O, Zhang H-T, Hupp JT \& LeIDNer CR 1989. Electrochemical assembly of metallo- polymeric films via reaction of coordinated 5-chlorophenanthroline. Inorg Chem 28: 1533-1537.

Kalyanasundaram K 1992. Photochemistry of Polypyridine and Porphyrin Complexes. New York: Academic Press.

LeHN J-M 1988. Supramolecular Chemistry (Nobel Lecture). Angew Chem Int Ed Engl 27: 89.

Toma HE \& ARaKi K 2000. Supramolecular assemblies of ruthenium complexes and porphyrins. Coord Chem Rev 196: 307-329.

Toma HE, Matsumoto FM \& Cipriano C 1993. Spectroelectrochemistry of the hexanuclear cluster $\left[\mathrm{Ru}_{3} \mathrm{O} \text { (acetate }\right)_{6}-\mu$-(pyrazine $\left.)_{3}-\left\{\mathrm{Fe}(\mathrm{CN})_{5}\right\}_{3}\right]$ and of its modified nickel electrode in aqueous solution. J Electroanal Chem 346: 261-270. 